\title{
Engagement of patients with psychosis in the consultation: conversation analytic study
}

\author{
Rosemarie McCabe, Christian Heath, Tom Burns, Stefan Priebe
}

\begin{abstract}
Unit for Social and Community

Psychiatry, Barts and the London School of Medicine, Newham Centre for Mental Health, London E13 8SP Rosemarie McCabe senior research fellow Stefan Priebe professor

Management Centre, King's College London, Franklin-Wilkins Building, London SE1 8WA

Christian Heath professor of work and organisations

Department of Psychiatry, St George's

Hospital Medical

School, London SW17 0RE

Tom Burns professor of community psychiatry Correspondence to: R McCabe r.mccabe@ qmul.ac.uk
\end{abstract}

BMJ 2002;325:1148-51

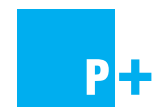

Transcripts and the transcript conventions appear on bmj.com

\begin{abstract}
Objective To investigate how doctors engage with patients with psychotic illness in routine consultations. Design Conversation analysis of 32 consultations between psychiatrists and patients with schizophrenia or schizoaffective disorder.

Setting Two psychiatric outpatient clinics in east London and south west London.

Participants 7 psychiatrists and 32 patients with schizophrenia or schizoaffective disorder.

Main outcome measure Mutual engagement in communication during the consultation.

Results Patients actively attempted to talk about the content of their psychotic symptoms in consultations by asking direct questions, repeating their questions and utterances, and producing these utterances in the concluding part of the consultation. In response, doctors hesitated, responded with a question rather than with an answer, and smiled or laughed (when informal carers were present), indicating that they were reluctant to engage with patients' concerns about their psychotic symptoms.

Conclusions Patients repeatedly attempted to talk about the content of their psychotic symptoms, which was a source of noticeable interactional tension and difficulty. Addressing patients' concerns about their illness may lead to a more satisfactory outcome of the consultation and improve engagement of such patients in the health services.
\end{abstract}

\section{Introduction}

The NHS plan promises substantial financial investment, which will fund both new mental health service teams and additional medical staff. ${ }^{1}$ Some of these initiatives, such as assertive outreach teams, are specifically designated to address the priority of engaging patients with severe psychotic disorders in the mental health services. ${ }^{2}$ Non-engaged patients are more unwell and socially impaired than those who are successfully engaged in services. ${ }^{3}$ The idea behind the new initiatives is that, to increase engagement in the services, patients with severe and enduring mental illness need at least more service input and perhaps even qualitatively different input. Although these additional teams may soon be in place, little is known about what inputs will make them more responsive to the needs of patients. ${ }^{1}$

In practice, engagement with services means engagement with the clinicians in a service who provide treatment. An approach that is gaining increasing attention in the study of medical consultations is ethnomethodology and conversation analysis. ${ }^{4}$ It examines the practices through which participants produce, recognise, and coordinate their actions and activities with each other. The focus on naturalistic interactions makes this method particularly suited to identifying patients' needs as they arise in service encounters. Two studies have been conducted on the psychiatrist-patient interaction: how psychiatrists conduct intake interviews and how psychiatrists identify delusions. ${ }^{5}{ }^{6}$ By using ethnomethodological and conversation analytic techniques, we analysed how psychiatrists and patients with psychotic illness engage with each other in routine consultations.

\section{Participants and methods}

We asked patients meeting criteria for a diagnosis of schizophrenia or schizoaffective disorder according to the Diagnostic and Statistical Manual of Mental Disorders, fourth edition, attending two psychiatric outpatient clinics in east London and south west London to participate in our study. An independent researcher approached consecutive attenders between June 2000 and June 2001 in the waiting room. Overall, 32 of 61 (52\%) people gave written informed consent. Seven of nine randomly selected psychiatrists working across five catchment areas agreed to participate. We videotaped 32 naturalistic psychiatrist-patient interactions. We obtained ethical approval for our study from the local research ethics committees.

\section{Analysis}

We examined the recordings and written transcripts of every consultation. We transcribed talk with Jefferson's orthography to analyse the characteristics of speech delivery, such as pauses, overlap, stress, intonation, and pace. ${ }^{7}$ We also transcribed visual and tactile features of the participants. We examined the recordings and transcripts to identify systematic and recurrent patterns of interaction across the consultations. ${ }^{4}$ We have simplified the verbatim material, which does not include detailed transcription symbols (see box 1 on bmj.com). These are retained in the boxes on bmj.com.

\section{Results}

Eighteen (56\%) of the patients were male. Overall, $50 \%$ of the sample (16 patients) were white British, 28\% (9) were Asian, 13\% (4) were African, and 9\% (3) were African-Caribbean. Twenty eight $(87 \%)$ were unemployed and 35\% (11) lived alone. The patients' ages ranged from 28-66, and they had a mean length of illness of 14.2 (SD 9.8) years. All the psychiatrists were male, and six were consultants. Consultations lasted around 15 minutes. Informal carers (for example, partner, parent) were present in one third of the consultations.

An average consultation involved the psychiatrist reviewing the patient's mental state, drugs and associated side effects, daytime activities (for example, attendance at a day facility, work, training), social activities, living arrangements, finances, and contact with other mental health professionals. Not every topic was covered in every consultation, and psychiatrists varied in how they addressed each topic. The consultation 
typically started with the psychiatrist asking how the patient had been and often asking specific questions about mood, sleep, appetite, thoughts, and symptoms. This sometimes involved eliciting the carer's account of how the patient had been. Patients' participation in the consultation predominantly involved responding to psychiatrists questions to inform them about their wellbeing and the effect of treatment (drugs, rehabilitation) since the last consultation.

\section{Patients' attempts to talk about their psychotic symptoms}

Specific talk about psychotic symptoms occurred about 1.4 times (range $0-4$ ) per interaction, lasted on average 67 seconds, and was started by doctors on 21 occasions, by patients on 22 occasions, and by a carer on one occasion. In general, doctors tended to ask about the frequency of these symptoms or to refer to their severity when the patient was on different kinds of drugs, whereas patients actively attempted to talk about their psychotic symptoms. In addition to telling their troubles and describing their symptoms, ${ }^{9}$ patients also asked the doctor's opinion about the cause of their troubles and about others' disbelief in relation to their experience, accounted for why they had their symptoms or illness, or discussed the pros and cons of drugs with respect to the severity of their symptoms.

We identified two situations when the patient attempted to talk about their psychotic symptoms. Firstly, when the preceding interaction had created an opportunity for the patient to talk about their experience and, secondly, when patients interjected or even inappropriately positioned this talk. Talk initiated through interjection or inappropriate positioning indicated that these concerns were not easily introduced. When patients did succeed in raising the topic of their concerns, it was often a source of tangible interactional problems.

In box 2 (see bmj.com) the psychiatrist asks the patient how he is quite early on in the consultation. The patient uses this second position of responding to the psychiatrist's question to report feeling afraid and thinking that everyone hates him. The doctor responds with "oh why?" "Oh" is often used to indicate receipt of information and acts to accept the truth or adequacy of that information. ${ }^{10}$ The subsequent animated "why?" promotes the patient to continue informing the doctor. After the patient says "well because I think everyone hates me," the doctor acknowledges with "yeah" (line 11) and looks down to write in the patient's notes. The patient continues telling his troubles (lines 13-26), which are punctuated by many pauses where the doctor might reply but withholds response (lines 14,20 , and 22). He responds verbally only with the minimal token acknowledgement of "mm." The patient finishes his account (line 26), which is followed by a pause of 7 seconds. The doctor then looks up from the notes to ask the patient's mother what she can tell him. Through his vocal and visual conduct, the doctor successfully realigns the focus of consultation away from the patient's disclosure of his symptoms to the mother's version of the troubles. The patient is provided with no further opportunity at that stage of the consultation to discuss the character of his symptoms.
The patient does not, however, abandon all attempts to discuss the details of his symptoms (see box 3 on bmj.com). As the doctor and patient's mother are finalising the arrangements for the next consultation, the patient interjects with "why don't people believe me when I say I'm God" (see box 4 on bmj.com). This interjection is positioned just as the doctor utters "so" after the mother's confirmation of the arrangements; an utterance that foreshadows the end of the consultation. ${ }^{11}$ The interjection forestalls progression into the close of the consultation and encourages the doctor to reopen discussion of one of the more important symptoms of the patient (see box 5 on bmj.com). ${ }^{12}$

The patient's formulation as a direct question (line 3 in box 4; see also box 6 on bmj.com) departs from the more typical communicative pattern in doctor-patient interaction-that is, question (doctor), answer (patient), acknowledgment (doctor)-with doctors asking more questions than patients. ${ }^{5}{ }^{1314}$ On being asked a question the recipient (doctor) is expected to provide a relevant response. ${ }^{15}$ If he or she fails to do so this behaviour is accountable-that is, the speaker (the patient) makes sense of it in terms of the recipient (doctor) having some problem in responding. ${ }^{15}$ In our data (see box 7 on bmj.com), the questions posed by the patients are a source of some interactional tension as patient and doctor attempt to realign the focus and trajectory of the consultation in a different direction.

The doctor's response to the patient's question (line 8 in box 4 on bmj.com) about why people don't believe him when he says he is God is a question to the patient "what should I say now?" Responding with a question to a question not only marks its problematic status, but the wording of the question conveys the doctor's difficulty in finding a way to respond. In general, the doctor's response to patients' questions about psychotic symptoms are punctuated by lengthy pauses, both before and during their responses, and hesitating noises such as "well," "eh," and "ehm" (see box 7 on bmj.com). These delay devices indicate reluctance or discomfort on being asked to respond to these questions..$^{15}$ Although the doctor's questions follow this hesitation, they do allow a continuation of the topic while avoiding taking a position in relation to the problematic utterance, a typical strategy used by professionals in different therapies.

After the doctor responds with the question, he laughs. This was characteristic of responses when carers were present. In box 8 (see bmj.com), the patient in response to a question from the doctor talks about why she got sick. Her husband is also present. At the end of the patient's utterance about why she got sick, the doctor smiles, then laughs, pauses, and says "ye" quietly. The patient seems to be sensitive to this particular response and asks (line 6) whether he believes what she has said. There is a short pause, her husband laughs (line 8), and the doctor, while smiling, delivers an assessment of what the patient thinks as a question "so you think somebody's done something to you?" continued later (line 15) with "like some kind of black magic kind of thing?"

Although it is not possible to present a detailed analysis of how the doctors' and carers' laughter is related to each other, in some cases the carer starts smiling or laughing before the doctor (see box 4 on bmj.com), and in other cases it is the doctor who smiles 
or laughs first (see box 8 on bmj.com). The reluctance to respond to patients' concerns cannot be explained by a disruption in a two way doctor-carer conversation as it also occurs in two way doctor-patient conversations.

\section{Discussion}

Patients with psychotic illness actively attempted to talk about the content of their symptoms during routine consultations. Some patients explicitly articulated that telling others, including psychiatrists, about these symptoms was problematic. Despite this, they clearly attempted to discuss their psychotic symptoms and actively sought information during the consultation about the nature of these experiences and their illness.

When patients attempted to present their psychotic symptoms as a topic of conversation, the doctors hesitated and avoided answering the patients' questions, indicating reluctance to engage with these concerns. ${ }^{15}$ This reluctance might be institutional-for example, it is not considered helpful or productive to deal with the content of patients' symptoms. The presence of carers also seemed to influence the patients' ability to express their concerns. When a carer was present, the doctor also smiled or laughed in response to patients' assessments of and questions about their symptoms. In telling about troubles it is usually the teller who laughs and the recipient who produces a serious response. ${ }^{16} \mathrm{In}$ medical interactions, laughter tends to be used more by patients than by doctors, often for delicate interactional tasks. ${ }^{17}{ }^{18}$ In our study, the doctors' use of laughter seemed to be problematic as a response to serious talk (questions) from the patient and may have indicated embarrassment when faced with such delicate questions from patients about the causes of their distress.

Research in general practice has shown that patient centred skills, particularly when giving information and counselling, are related to increased treatment compliance, improved satisfaction, and both decreased emotional distress and decreased burden of symptoms. ${ }^{19-23}$ The growing number of organisations started by patients and carers (for example, the Hearing Voices Network) to provide an opportunity to talk about psychotic symptoms reflects a wish for this aspect of the illness to be addressed.

Our study was conducted across two services in urban areas, which may limit the generalisability of our findings. Recruitment bias may have existed, as participants were consecutive attenders at outpatient clinics. In addition, identifying patients' needs from what they say in routine consultations requires validation with other methods. The strengths of our study are that it is the first of its kind to focus on interactional engagement with patients with psychotic illness, it employed an analytic method with robust validation procedures, and it identified systematic patterns of interaction across the consultations.

\section{Conclusions}

Psychotic patients actively attempt to talk about their symptoms, especially the psychotic content. These findings are based on a qualitative study and it is not known to what extent these behaviours are linked to other outcomes. However, given the well established association between interactional engagement and outcomes in pri-
What is already known on this topic

Patients with psychotic illness are difficult to engage in the health services

No research has been published on how doctors engage with these patients in consultations

What this study adds

Patients actively attempt to talk about the content of their psychotic symptoms

Doctors' reluctance and discomfort in engaging with this topic is apparent

Addressing patients' concerns may lead to a more satisfactory outcome of the consultation and improve engagement with services

mary care research, addressing patients' concerns about their psychotic symptoms might facilitate better engagement with services. ${ }^{20-23}$ At least it does seem that such an approach would meet the immediate needs of a major number of patients, leading to a more satisfactory outcome of the consultation.

We thank Sarajane Battachary and Giovanni Polizzi for recording the consultations, the participants, and Sanna Vehviläinen for helpful comments. The analysis benefited from data sessions hosted by the Work, Interaction, and Technology group at King's College.

Contributors: RM was involved in the conception and design of the study, collection, analysis, and interpretation of the data, writing the article, and approval of the final manuscript; she will act as guarantor for the paper. $\mathrm{CH}$ contributed to the design of the study, interpretation of the data, and revision and approval of the final manuscript. TB contributed to the design of the study, collection and interpretation of the data, and revision and approval of the final manuscript. SP was involved in the conception and design of the study, interpretation of data, critical revision of the article, and approval of the final manuscript.

Funding: None.

Competing interests: None declared.

1 Department of Health. The NHS plan: a plan for investment, a plan for reform. London: Department of Health, 2000.

2 Department of Health. Modern standards and service models:national service framework for mental health. London: Department of Health, 1999.

3 Killaspy H, Banerjee S, King M, Lloyd M. Prospective controlled study of psychiatric out-patient non-attendance. Br J Psychiatry 2000;176:160-5.

4 Drew P, Chatwin J, Collins S. Conversation analysis: a method for research into interactions between patients and healthcare professionals. Health Expect 2001;4:58-70.

5 Bergmann J. Veiled morality: notes on discretion in psychiatry. In: Drew P, Heritage J, eds. Talk at work. Cambridge: Cambridge University Press, 1992.

6 Palmer D. Identifying delusional discourse: issues of rationality, reality and power. Sociology Health Illn 2000:22:661-78.

7 Sacks H, Schegloff E, Jefferson G. A simplest systematics for the organisation of turn-taking in conversation. Language 1974;50:696-735.

8 Peräkylä A. Validity and reliability in research based on tapes and transcripts. In Silverman D, ed. Qualitative analysis: issues of theory and method. London: Sage, 1997.

9 Jefferson G, Lee JRE. The rejection of advice: managing the problematic convergence of a "troubles-telling" and a "service encounter." In: Drew P, Heritage J, eds. Talk at work. Cambridge: Cambridge University Press, 1992.

10 Heritage J. A change-of-state token and aspects of its sequential placement. In: Atkinson JM, Heritage J, eds. Structures of social action: studies in conversation analysis. Cambridge: Cambridge University Press, 1984. 1 Levinson S. Pragmatics. Cambridge: Cambridge University Press, 1983.

11 Levinson S. Pragmatics. Cambridge: Cambridge University Press, 1983. Peräkylä A. AIDS counselling: institutional inter
Cambridge: Cambridge University Press, 1995.

13 Ten Have P. Doing conversation analysis: a practical guide. London: Sage, 1999

14 Frankel R. Talking in interviews: a dispreference for patient-initiated questions in physician-patient encounters. In: Psathas G, ed. Interaction competence. Lanham, MD: University Press of America, 1990. 
15 Pomerantz A. Agreeing and disagreeing with assessments: some feature of preferred/dispreferred turn shapes. In: Atkinson JM, Heritage J, eds. Structures of social action. Cambridge: Cambridge University Press, 1984.

16 Jefferson G. On the organization of laughter in talk about troubles. In: Atkinson JM, Heritage J, eds. Structures of social action. Cambridge: Cambridge University Press, 1984.

17 Haakana M. Laughter as a patient's resource: dealing with delicate aspects of medical interaction. Text 2001:21:187-219.

18 Haakana M. Laughter in medical interaction: from quantification to analysis, and back.J Sociolinguistics 2002:6:207-35

19 Stewart M. What is a successful doctor-patient interview? A study of interactions and outcomes. Soc Sci Med 1984;19:167-75.

20 Roter DL, Hall JA, Katz NR. Relations between physicians' behaviours and analogue patients' satisfaction, recall and impressions. Med Car 1987;25:437-51

21 Bertakis D, Roter D, Putnam SM. The relationship of physician medica interview style to patient satisfaction. J Fam Pract 1991;32:175-81.

22 Roter DL, Hall JA, Kern DE, Barker R, Cole KA, Roca RP. Improving physicians' interviewing skills and reducing patients' emotional distress: a randomized clinical trial. Arch Intern Med 1995;155:1877-84.

23 Little P, Everitt H, Williamson I, Warner G, Moore M, Gould C, et al. Observational study of effect of patient centredness and positive approach on outcomes of general practice consultations. BMJ 2001;323:908-11.

(Accepted 1 August 2002)

\section{Commentary: Understanding conversation}

John Skelton

McCabe and colleagues' study raises fascinating issues about conversation analysis as a methodology and about the way that doctors and patients with psychotic illness communicate.

Conversation analysis is one of several related approaches that sought to take language from the grammarian's study, where linguists could learn what language was, to the real world, where they could learn how it was used, with its confusions, false starts, and misunderstandings. Conversation analysis has helped in the understanding of not merely rules of usage - the rules of grammar-but rules of use as well. ${ }^{1} \mathrm{I}$ was asked recently, for example, whether doctors call patients "sir" and "madam" in the United Kingdom: a pertinent question about use that had never occurred to me.

This kind of inquiry, however, has its costs. Many rules of use are of limited generalisability. Conversation has a limited number of openings-"hello," "morning," and so on; but what happens thereafter is normally less certain. Areas of local predictability may exist, but it is usually hard to say what absolutely must happen next.

As far as a researcher is concerned lack of generalisability means the data look vulnerable. In addition, the study becomes essentially discursive rather than reductive, and qualitative rather than quantitative. It is not really in the nature of conversation analysis or its associated techniques to offer simple, straightforward messages. Rather-and this is the strength of McCabe and colleagues' study-it offers the reader a way of thinking about the obvious and rediscovering it as pro- found. Thus, at one level they show that doctors have trouble talking to patients with psychotic illness. Hardly dynamite. But observe how a well executed and well illustrated study helps to get under the surface of this kind of statement.

The point of normal conversations-the central insight of conversation analysis-is that they are sequential. You say something, I respond, you build on my response. Conversation is governed by various conventions -we seek to be polite, relevant, and so on. But what happens if these conventions are in conflict? A stranger on a train may express outrageous views that we pretend to accept because we never have to see them again. But if we have a therapeutic relationship, what then?

McCabe and colleagues' study shows experienced doctors failing to overcome the normal conventions of interaction, among which are that seldom does anyone have the right directly to tell someone they're wrong. But can a doctor tell a patient they can believe they're God if they want, any more than a teacher can tell a student that the sum of 2 and 2 is a matter of personal choice? These conversations show us that doctors need help in understanding and articulating the relation between the rules of ordinary talk and the rules of the therapeutic talk their patients require. If they cannot develop this understanding then, as the doctor quoted says, "what shall I say?"

1 Hymes DH. On communicative competence. In: Pride JB, Holmes J, ed Sociolinguistics. Harmondsworth: Penguin, 1972:269-93.
Interactive Skills Unit, Department of Primary Care and General Practice, University of Birmingham, B15 2TT John Skelton director

j.r.skelton@

\section{Submitting articles to the $B M J$}

We are now inviting all authors who want to submit a paper to the $B M J$ to do so via the web (http://submit.bmj.com).

Benchpress is a website where authors deposit their manuscripts and editors go to read them and record their decisions. Reviewers' details are also held on the system, and when asked to review a paper reviewers will be invited to access the site to see the relevant paper. The system is secure, protected by passwords, so that authors see only their own papers and reviewers see only those they are meant to. The system is run by Highwire Press, who host bmj.com, and is already being used by 30 journals, including most of the BMJ Publishing Group's specialist journals.

For authors in particular the system offers several benefits. The system provides all our guidance and forms and allows authors to suggest reviewers for their paper-something we'd like to encourage. Authors get an immediate acknowledgement that their submission has been received, and they can watch the progress of their manuscript. The record of their submission, including editors' and reviewers' reports, remains on the system for future reference.

Anyone with an internet connection and a web browser can use the system.

The system itself offers extensive help, and the BMJ's editorial office is geared up to help authors and reviewers if they get stuck. We see Benchpress as part of our endeavour to improve our service to authors and reviewers and, as always, we'd welcome feedback.

Benchpress is accessed via http://submit.bmj.com or via a link from bmj.com 